CLINICAL STUDY

\title{
Circulating levels of incretin hormones and amylin in the fasting state and after oral glucose in GH-deficient patients before and after GH replacement: a placebo-controlled study
}

Jens O L Jørgensen, Anne M Rosenfalck ${ }^{2}$, Sanne Fisker, Birgit Nyholm, Mark S Fineman, Ole Schmitz, Sten Madsbad ${ }^{2}$, Jens J Holst ${ }^{1}$ and Jens S Christiansen

Medical Department M (Endocrinology and Diabetes), Aarhus University Hospital, Aarhus, Denmark, ${ }^{1}$ Institute of Medical Physiology C, Panum Institute, University of Copenhagen, Copenhagen, Denmark and ${ }^{2}$ Department of Endocrinology, Hvidovre Hospital, Copenhagen, Denmark (Correspondence should be addressed to J O L Jorgensen, Medical Department M, Aarhus Kommunehospital, DK 8000 C, Aarhus, Denmark; Email: jolj@dadlnet.dk)

\begin{abstract}
Objective: Hyperinsulinemia in association with GH excess is considered a compensatory response to insulin resistance, but the possibility of alternative insulinotropic mechanisms has not been investigated in vivo. It is also unknown how GH influences the secretion from pancreatic $\beta$-cells of amylin, a peptide which regulates prandial glucose homeostasis and may be linked to development of $\beta$-cell dysfunction. We therefore measured plasma concentrations of two gut insulinotropic hormones, glucagon-like peptide 1 (GLP-1) and glucose-dependent insulin-releasing peptide (GIP), and total as well as non-glycosylated amylin, in $24 \mathrm{GH}$-deficient adults before and after 4 months of GH replacement (daily evening injections of $2 \mathrm{IU} \mathrm{GH} / \mathrm{m}^{2}$ ).

Design: Double-blind, placebo-controlled, parallel study.

Methods: All participants underwent an oral glucose tolerance test (OGTT) at 0 and 4 months.

Results: A 33\% suppression of fasting GLP-1 concentrations was measured in the GH group at 4 months $(P=0.02)$, whereas a non-significant increase occurred in the placebo group $(P=0.08)$. Fasting levels of GIP and amylin did not change significantly after 4 months in either group. The incremental response in GLP-1 during the OGTT was significantly lower after GH treatment as compared with both baseline $(P=0.02)$ and the response in the placebo group $(P=0.03)$. The stimulation of GIP secretion following OGTT was similar on all occasions. The OGTT-induced incremental response in non-glycosylated amylin was moderately elevated after $\mathrm{GH}$ treatment as compared with placebo $(P=0.05)$. Plasma concentrations of glucose and insulin, both in the fasting state and after the OGTT, were higher after GH treatment, but the ratio between amylin and insulin remained unchanged.

Conclusions: GH-induced hyperinsulinemia is accompanied by proportionate elevations in amylin concentrations and a blunting of gut GLP-1 secretion. The mechanisms underlying the suppression of GLP-1 remain to be elucidated.
\end{abstract}

European Journal of Endocrinology 143 593-599

\section{Introduction}

The effects of growth hormone $(\mathrm{GH})$ on insulin secretion and glucose metabolism have been studied over several decades (1). Active acromegaly as well as sustained high-dose GH administration in normal adults is associated with hyperinsulinemia and insulin resistance $(2,3)$. By contrast, GH-deficient children may exhibit hypoinsulinemia and fasting hypoglycemia (4). Hyperinsulinemia associated with prolonged $\mathrm{GH}$ exposure is traditionally assumed to be secondary to induction of both hepatic and peripheral insulin resistance. Increased insulin levels and insulin resistance have also been documented in GH-deficient adults during acute and prolonged replacement with GH in moderately supraphysiological doses $(5,6)$.

There is, however, also evidence to suggest alternative insulinotropic effects of GH. Co-administration of i.v. $\mathrm{GH}$ and glucose has been shown to exaggerate the increment in plasma insulin in normal and GHdeficient children (7), and i.v. GH administration in dogs acutely increases portal insulin levels (8). Moreover, GH stimulates insulin production in pancreatic $\beta$ cells in vitro, and these cells express functional $\mathrm{GH}$ receptors, which during activation stimulate insulin gene expression and mitotic activity (9). These studies suggest that stimulatory effects of $\mathrm{GH}$ on $\beta$-cell function in vivo may involve several independent pathways. 
To further our understanding of this important aspect of GH action we have evaluated the circulating levels of pertinent markers and regulators of $\beta$-cell activity in GH-deficient adults. All patients underwent an oral glucose tolerance test (OGTT) before and after GH substitution in a placebo-controlled, parallel design.

We measured basal and glucose-stimulated plasma concentrations of glucagon-like peptide 1 (GLP-1) and glucose-dependent insulin-releasing peptide (GIP). These gut factors, which are released by oral nutrients, are known to stimulate insulin secretion $(10,11)$. The secretion of GIP and GLP-1 accounts to a large extent for the so-called incretin effect, i.e. the phenomenon that oral glucose elicits a greater insulin response than an equivalent amount of i.v. glucose. Plasma amylin levels were also measured, since this pancreatic polypeptide, which is co-secreted with insulin, not only reflects islet cell function but has been shown to exert effects on insulin secretion and prandial glucose metabolism $(12,13)$.

\section{Patients and methods}

\section{Patients}

Twenty-four adults (6 females, 18 males) with a mean \pm s.E. age of $38 \pm 2$ years, and a mean \pm s.E. body mass index of $28.7 \pm 1.0$ were included. Pituitary disease was adult-onset in 17 cases and childhood-onset in 7 cases ( 9 non-functioning pituitary adenoma, 2 prolactinoma, 3 Cushing disease, 5 craniopharyngioma and 5 others). All patients except one had additional pituitary deficits for which conventional replacement therapy was continued unchanged during the study period (19 patients received hydrocortisone, thyroxine and sex steroids, one patient received hydrocortisone + thyroxine, whereas two received sex steroids and one patient received only desmopressin). Prior to study entry GH deficiency was verified or reconfirmed by a stimulated GH response less than $5 \mu \mathrm{g} / \mathrm{l}$ (mean \pm s.E. peak GH response: $1.0 \pm 0.3 \mu \mathrm{g} / \mathrm{l})$. The tests included insulin-induced hypoglycemia, arginine infusion and heat exposure. Mean baseline serum insulin-like growth factor-I (IGF-I) concentration was $109 \pm 40 \mu \mathrm{g} / \mathrm{l}$.

\section{Study design}

In a randomized, double-blind, parallel design the patients were allocated to 4 months of either GH (Norditropin; Novo Nordisk, Gentofte, Denmark) or placebo. The medication was administered as daily s.c. self-injections performed in the evening. During the initial 6 weeks the GH dose was gradually increased to a daily target dose of $2 \mathrm{IU} / \mathrm{m}^{2}$. All measurements were performed both at baseline and after the 4 month treatment. The study was approved by the regional and national ethical committees, and by the national health authorities.

\section{OGTT}

The patients were admitted to hospital at $0800 \mathrm{~h}$ after an overnight fast of at least $10 \mathrm{~h}$. An i.v. cannula was inserted into an antecubital vein for blood sampling. Baseline samples were drawn at $-15,-10$, and $-5 \mathrm{~min}$. At time $0,75 \mathrm{~g}$ glucose monohydrate were administered orally in $300 \mathrm{ml}$ tap water. Blood was sampled at $10 \mathrm{~min}$ intervals for the first hour, followed by $15 \mathrm{~min}$ intervals for the next $1.5 \mathrm{~h}$, and finally after $3 \mathrm{~h}$.

\section{Assays}

Total as well as non-glycosylated amylin immunoreactivity was measured as previously described (14). For both analytes the detection limit was $<2.0 \mathrm{pmol} / \mathrm{l}$, and the intra- and interassay coefficients of variation (CVs) were less than $15 \%$. GIP and GLP-1 concentrations in plasma were measured after extraction of plasma with $70 \%$ ethanol (v/v, final concentration). For the GIP RIA (15) we used C-terminally directed antiserum R65, which cross-reacts fully with human GIP but not with the so-called GIP 8000, whose chemical nature and relationship to GIP secretion is uncertain. Human GIP and ${ }^{125} \mathrm{I}$-human GIP $(70 \mathrm{MBq} / \mathrm{nmol})$ were used for standards and tracer. The plasma concentrations of GLP1 were measured against standards of synthetic GLP-1 7-36 amide using antiserum code no. 89390 , which is specific for the amidated C-terminus of GLP-1 and therefore does not react with GLP-1-containing peptides from the pancreas (16). The results of the assay accurately reflect the rate of secretion of GLP-1 because the assay measures the sum of intact GLP-1 and the primary metabolite, GLP-1 9-36 amide, into which GLP1 is rapidly converted (17). For both assays sensitivity was below $1 \mathrm{pmol} / \mathrm{l}$, and intraassay $\mathrm{CV}$ below $6 \%$ at $20 \mathrm{pmol} / \mathrm{l}$. Corrections are made for an inherent 30\% loss of standard in the extraction procedure. Plasma glucose was measured in duplicate by the glucose oxidase method (Beckman Instruments, Fullerton, CA, USA). C-peptide and insulin were determined by commercial assays (DAKO, Diagnostics Ltd, Cambs, UK).

Data on glucose, insulin and C-peptide have previously been published (18).

\section{Statistical analysis}

Basal levels of each parameter were compared using Student's $t$-test for paired (0 vs 4 months) and unpaired (GH vs placebo groups) data. To test for changes in plasma levels of each parameter with time during the OGTT, one-way ANOVA was performed. Comparisons between the temporal changes in each parameter at baseline and after 4 months were analyzed by two-way ANOVA (MANOVA) (time and condition). Area under the plasma curve (AUC) of each parameter was estimated according to the trapezoidal rule. Differences in AUC were analyzed within each treatment group ( 0 vs 4 
Table 1 Fasting concentrations of GLP-1, GIP, total amylin and non-glycosylated amylin in placebo and GH-treated GH-deficient patients at baseline and after 4 months.

\begin{tabular}{|c|c|c|c|c|c|c|c|}
\hline & \multicolumn{3}{|c|}{ Placebo } & \multicolumn{3}{|c|}{ GH } & \multirow{2}{*}{$\frac{\text { GH vs placebo }}{P}$} \\
\hline & 0 & 4 & $P$ & 0 & 4 & $P$ & \\
\hline GLP-1 (pmol/l) & $6.3 \pm 1.6$ & $7.4 \pm 1.5$ & 0.08 & $8.6 \pm 0.8$ & $5.8 \pm 1.1$ & 0.02 & 0.007 \\
\hline GIP (pmol/l) & $17.4 \pm 6.4$ & $18.0 \pm 3.4$ & 0.93 & $15.8 \pm 3.0$ & $10.3 \pm 1.1$ & 0.15 & 0.39 \\
\hline Amylin $_{\text {tot }}(\mathrm{pmol} / \mathrm{l})$ & $7.3 \pm 1.5$ & $6.1 \pm 0.7$ & 0.36 & $3.3 \pm 0.6$ & $8.9 \pm 1.9$ & 0.19 & 0.11 \\
\hline Amylin non-glyc $(\mathrm{pmol} / \mathrm{l})$ & $2.3 \pm 0.4$ & $2.0 \pm 0.3$ & 0.45 & $3.3 \pm 0.6$ & $3.4 \pm 0.5$ & 0.83 & 0.59 \\
\hline
\end{tabular}

months) by Student's paired t-test, whereas the differences in AUC between $\mathrm{GH}$ and placebo, i.e. the true treatment effect, was analyzed by Student's unpaired $t$ test on $\Delta$-values. If necessary, logarithmic transformations were performed to obtain normality. $P$ values $<0.05$ were considered significant. Pearson's product moment correlation was used to measure the strength of association between GLP-1 and body composition variables. Results are expressed as means \pm s.E.

\section{Results}

\section{Fasting levels}

Plasma levels measured prior to ingestion of glucose during the OGTT in each treatment group at baseline and after 4 months are presented in Table 1. At baseline no differences between the two treatment groups were recorded. After 4 months a significant 33\% suppression of fasting plasma GLP-1 concentrations was measured in the $\mathrm{GH}$ group $(P=0.02)$, whereas a non-significant increase occurred in the placebo group $(P=0.08)$, which resulted in a highly significant treatment effect $(P=0.007)$. Fasting levels of GIP as well as total and glycosylated amylin did not change significantly after 4 months in either treatment group (Table 1).

Plasma concentrations of glucose, insulin, and Cpeptide at baseline did not differ between the two groups. Four months of $\mathrm{GH}$ treatment induced significant increments in fasting plasma concentrations of glucose and insulin (glucose (mmol/l): $5.0 \pm 0.1(0)$ vs $5.4 \pm 0.2(4)(P=0.05)$; insulin $(\mathrm{pmol} / \mathrm{l}): 38 \pm 9(0)$ vs $55 \pm 11(4)(P=0.02))$. No significant changes occurred in the placebo group.

\section{OGTT}

Highly significant increments in plasma concentrations of GLP-1, GIP, and amylin were recorded within each group during the OGTT both at baseline and after 4 months (Figs 1-3). When comparing baseline and 4 month OGTT data within each group by twoway ANOVA highly significant differences $(P<$ $0.001)$ in the responses were obtained in the $\mathrm{GH}$ group, but not in the placebo group. When expressed as AUC during OGTT the incremental response in
GLP-1 was significantly blunted after 4 months of GH as compared with baseline $(P=0.02)$, and the difference in $\Delta$-AUC (O vs 4 months) between the two treatment groups was also significant $(P=0.03)$ (Fig. 1). As compared with baseline data the AUC of non-glycosylated amylin during OGTT after 4 months tended to decrease in the placebo group $(P=0.1)$ and increase in the GH group $(P=0.2)$, which translated into a significant treatment effect $(P=$ 0.05) (Fig. 3).
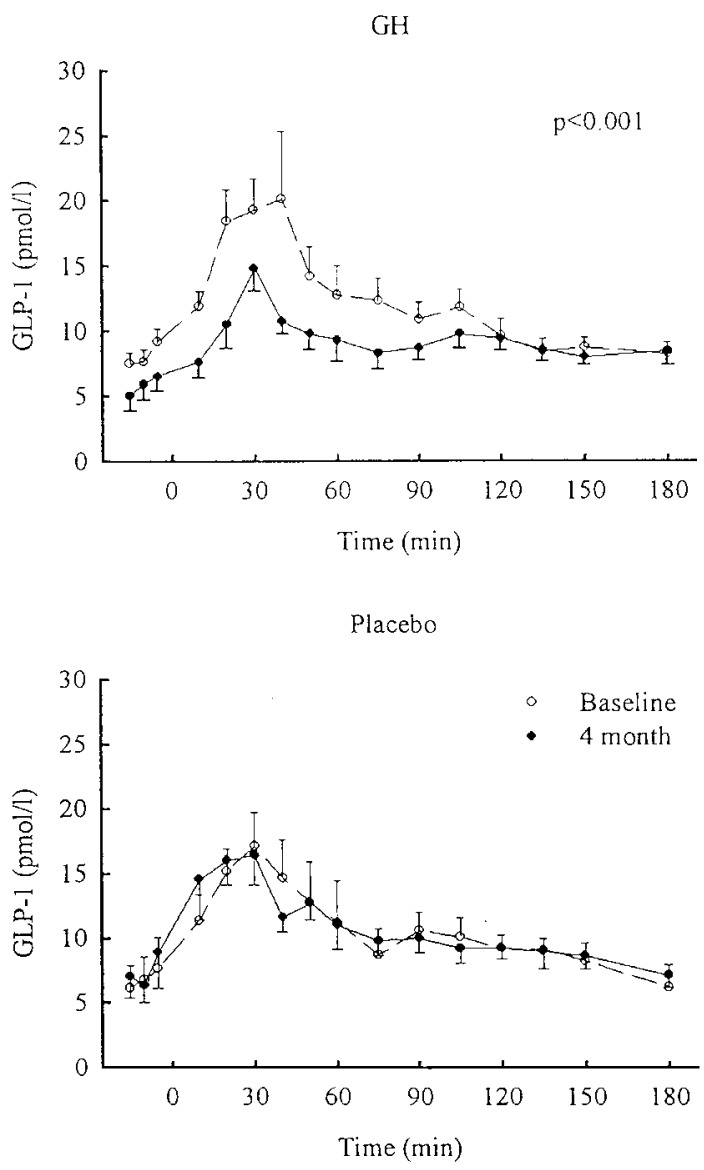

Figure 1 Mean \pm S.E plasma concentrations of GLP-1 before and during an OGTT performed at baseline (open symbols) and after 4 months of treatment (solid symbols) with either GH (upper panel) or placebo (lower panel). Oral glucose was administered at time 0. 

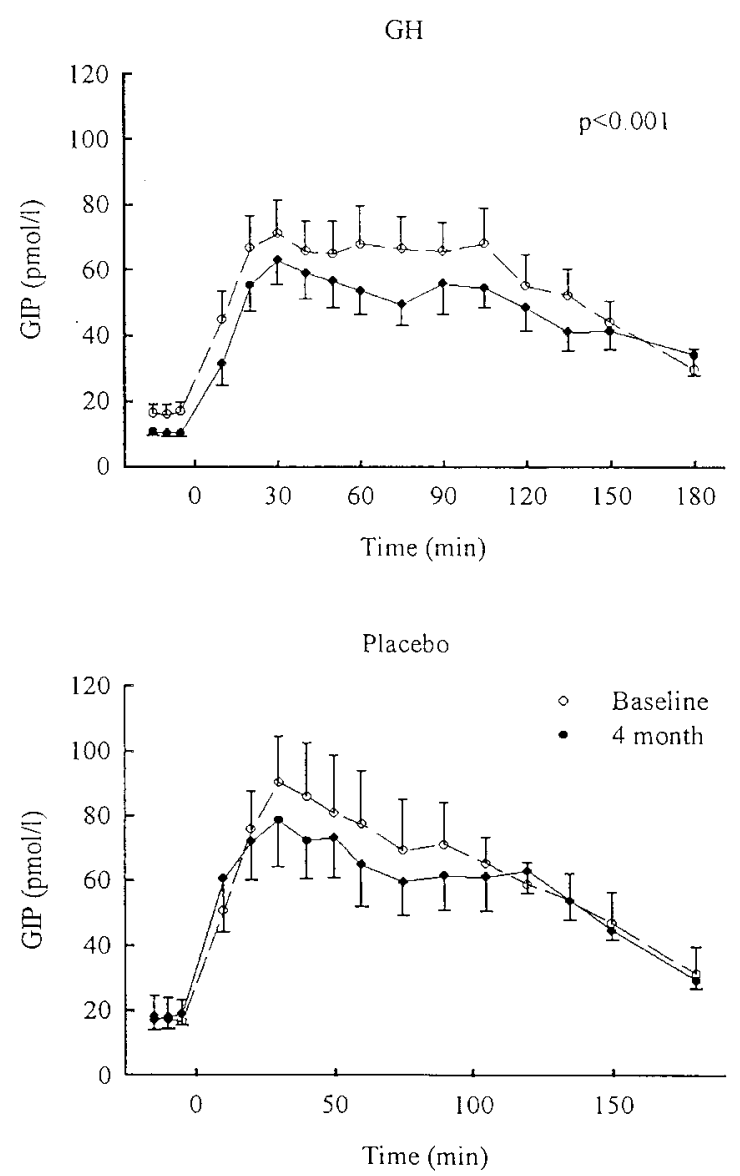

Figure 2 Mean \pm S.E. plasma concentrations of GIP before and during an OGTT performed at baseline (open symbols) and after 4 months of treatment (solid symbols) with either GH (upper panel) or placebo (lower panel). Oral glucose was administered at time 0.

Plasma glucose $\mathrm{AUC}_{\mathrm{AU}}$ during the OGTT was significantly higher after 4 months in the GH group, and a near-significant increment was observed in the corresponding plasma insulin AUC $_{\text {(glucose }}$ AUC $(\mathrm{mmol} / \mathrm{l} \times$ min): $1054 \pm 14(0)$ vs $1222 \pm 17$ (4) $(P=0.02)$; insulin $_{\mathrm{AUC}} \quad(\mathrm{pmol} / \mathrm{l} \times \min ): 17198 \pm 4660 \quad$ (0) $\quad$ vs $27067 \pm 1866(4)(P=0.07))$. No significant differences were recorded in $\mathrm{C}$-peptide $\mathrm{AUC}_{\mathrm{AU}}$.

A correlation matrix including basal as well as $\Delta$ values of GLP-1 and selected body composition variables did not disclose any significant correlations (data not shown).

\section{Discussion}

The main finding in the present study was a significant reduction in both basal and stimulated levels of GLP-1 following 4 months of GH replacement in hypopituitary adults, which occurred together with moderate elevations in insulin and amylin levels.

Hyperinsulinemia during $\mathrm{GH}$ exposure in vivo is a well-known feature, which traditionally is considered to be secondary to induction of peripheral and hepatic insulin resistance. The mechanisms underlying the insulin-antagonistic actions of $\mathrm{GH}$ are not fully characterized, but at the level of substrate metabolism a key finding is stimulation of lipolysis and lipid oxidation, which may cause the reduced uptake and oxidation of glucose (1) in striated muscle through activation of the glucose/fatty acid cycle (19). In the present study GH treatment significantly impaired insulin sensitivity and glucose tolerance, as previously published in detail (18). There is, however, also evidence for a more direct tropic effect of $\mathrm{GH}$ on the pancreatic $\beta$-cell. Addition of GH to cultured $\beta$-cells has been shown to stimulate insulin secretion and biosynthesis through binding and activation of the $\mathrm{GH}$ receptor (9), but the effect of $\mathrm{GH}$ on gut insulinotropic hormones has not previously been investigated. GLP-1 is produced and secreted by L cells of the gut and is a product of post-translational processing of the proglucagon gene $(11,20)$. Pancreatic alpha cells predominantly produce larger GLP-1 moieties, which are not measured by our assay. A major stimulus of GLP-1 secretion from the gut is the presence of intraluminal glucose and other nutrients $(11,20)$. A major effect of GLP-1 is stimulation of insulin secretion, and this effect appears to be receptor mediated, inasmuch as a specific receptor for GLP-1 has recently been cloned from human islets (21). In addition, GLP-1 decelerates gastric emptying and lowers gastric acid secretion. Apart from this, GLP-1 is also produced in specific brain nuclei and may act as a satiety signal following binding to hypothalamic receptors (11). The incretin effect of GLP-1 has been experimentally verified by combined administration of glucose and exogenous GLP-1 in healthy subjects, which resulted in augmented insulin secretion (22). The contribution of GLP-1 to the overall incretin effect has, however, been questioned since the inhibitory effect of GLP-1 on gastric emptying appears to reduce substrate-mediated insulin secretion at least during experimental conditions in healthy subjects. The insulinotropic effects of GLP-1 depend on increased glucose concentrations $(23,24)$, and this glucose dependency has been substantiated by administering GLP-1 i.v. following a mixed meal in type 2 diabetic patients, which significantly amplified post-prandial insulin concentrations resulting in a prolonged lowering of plasma glucose concentrations (25).

GH treatment also resulted in predictable significant changes in body composition in terms of reduced fat mass and increased fat mass (18). No data exist regarding the possible influence of body composition on GLP-1 secretory dynamics. The effects of acute or short-term administration of GH would help to disclose possible direct effects on GLP-1. Endogenous GH secretion in healthy subjects depends strongly on nutrient intake. Short-term and more prolonged fasting is associated with pronounced hypersomatotropinemia (26), whereas oral glucose ingestion suppresses 

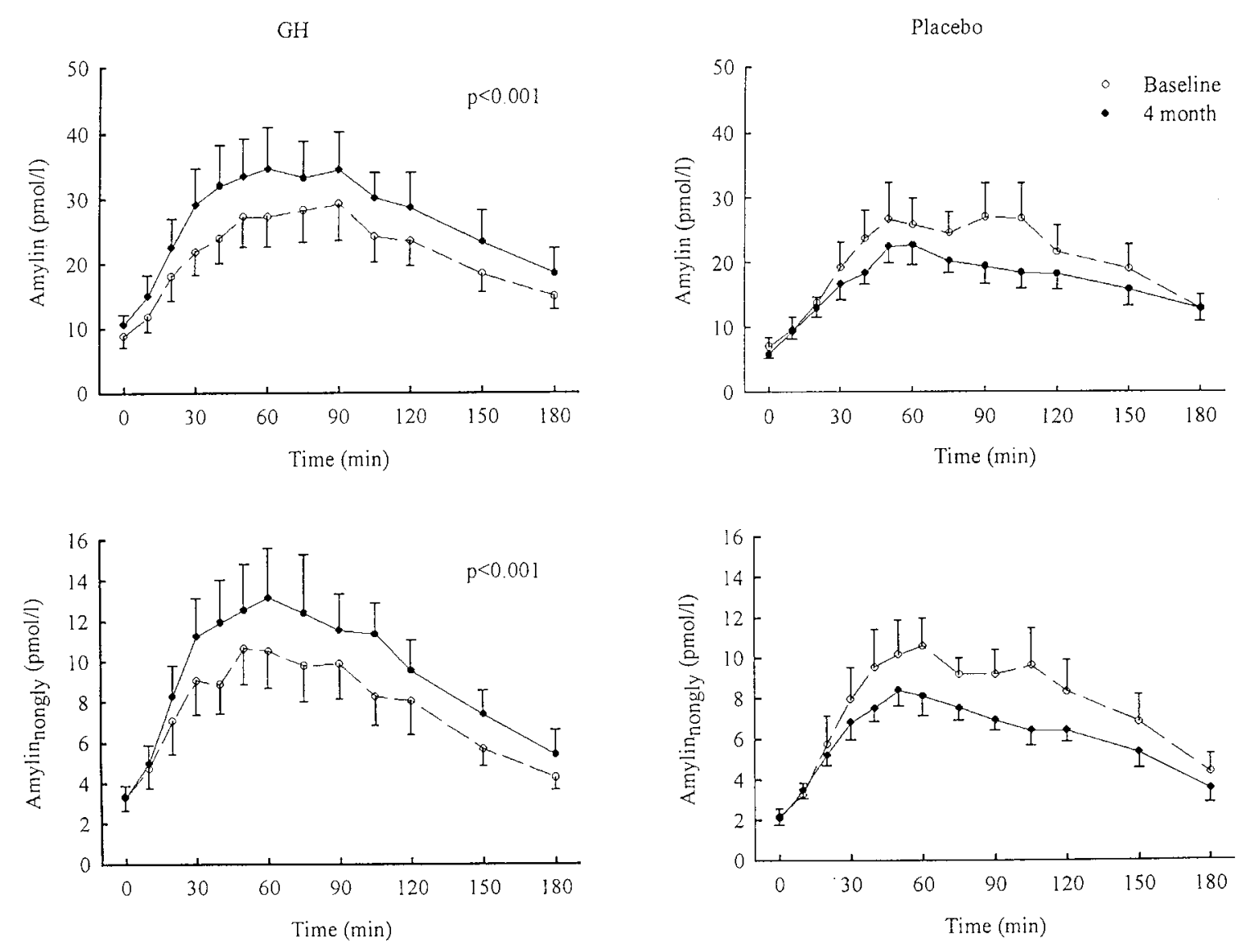

Figure 3 Mean \pm S.E. plasma concentrations of total amylin (upper panels) and non-glycosylated amylin (lower panels) during an OGTT performed at baseline (open symbols) and after 4 months of treatment (solid symbols) with either GH (left panels) or placebo (right panels). Oral glucose was administered at time 0 .

endogenous $\mathrm{GH}$ release. In the present study, GH was injected s.c. between 2000 and 2200 h, which implies that the ambient GH concentrations during the OGTT, which was performed in the morning, were low, albeit not returned to pre-injection levels (27). The observed effects on GLP-1 could also be caused by elevated total IGF-I concentrations, but our study design does not allow firm conclusions about the mechanisms underlying the suppression of GLP-1 following GH exposure. Based on teleological considerations it is not unexpected that $\mathrm{GH}$, which normally operates in the postabsorptive state to partition substrate metabolism from glucose utilization to mobilization of lipid stores, inhibits gut insulinotropic hormones. In all instances the study emphasizes that the effects of sustained GH exposure on glucose metabolism and insulin dynamics are not identical to those observed in other insulin resistant states such as type 2 diabetes, since fasting and stimulated GLP-1 levels are significantly elevated in newly diagnosed type 2 patients as compared with weight-matched controls (24).

The changes in plasma GIP concentrations following $\mathrm{GH}$ treatment were less clear since two-way ANOVA revealed a significant difference when comparing the response to the OGTT at baseline and 4 months, whereas no differences were found when comparing changes in $\mathrm{GIP}_{\mathrm{AUC}}$ between the two treatment groups. This reflects that a moderate reduction in the incremental GIP response was observed in both groups at 4 months. It is therefore concluded that $\mathrm{GH}$ treatment does not significantly affect GIP secretion. It is generally accepted that GIP is a major contributor to the incretin effect in normal subjects $(10,11)$, whereas this effect appears to be reduced in type 2 diabetes despite normal or elevated GIP levels (28).

As expected plasma amylin levels increased during the OGTT on all occasions, and this incremental response was moderately elevated following $\mathrm{GH}$ therapy. The amylin-to-insulin ratio (A/I) was, however, similar in all studies, which suggests that the amylin response in $\mathrm{GH}$-treated subjects increases in proportion to enhanced $\beta$-cell secretion. An increased A/I has been observed during the early phases of hyperglycemia in diabetic rodents (29), and it has been suggested that circulating amylin may induce insulin resistance and hence contribute to the pathogenesis of type 2 diabetes 
(13). In healthy adults infusion of a human amylin analog failed, however, to influence insulin sensitivity (30). It has also been speculated that deposition of islet amyloid, which is a known feature of type 2 diabetes, impairs $\beta$-cell function. Interestingly, co-administration of $\mathrm{GH}$ and dexamethasone in mice transgenic for human islet amyloid induced amyloid deposits and hyperglycemia (31). Our data do not, however, indicate that GH-induced insulin resistance and impaired glucose tolerance is associated with specific abnormalities in amylin secretion.

In summary, the insulinotropic effects of moderately supraphysiological GH exposure for 4 months in GHdeficient adults are accompanied by a reduction in basal and stimulated GLP-1 secretion, unchanged GIP levels, and a proportionate increase in amylin concentrations. These data suggest a hitherto unrecognized suppressive effect of GH on GLP-1 secretion the significance of which merits future studies. In particular, acute GH exposure timed according to GLP-1 stimulation could help to distinguish between possible direct and indirect effects of GH. We conclude that the effects of $\mathrm{GH}$ on $\beta$-cell function in human subjects involves other features than induction of insulin resistance.

\section{Acknowledgements}

Preparations of GH and placebo were supplied by Novo Nordisk, Copenhagen, Denmark. The study was supported by an unrestricted research grant from Novo Nordisk.

\section{References}

1 Møller N. The role of growth hormone in the regulation of human fuel metabolism. In Growth Hormone and Insulin-Like Growth Factor-I, pp 77-108. Eds A Flyvbjerg, H Ørskov \& KGMM Alberti. UK: John Wiley \& Sons Ltd, 1993.

2 Møller N, Schmitz O, Jørgensen JOL, Astrup J, Bak JF, Christensen SE et al. Basal and insulin stimulated substrate metabolism in patients with active acromegaly before and after adenomectomy. Journal of Clinical Endocrinology and metabolism $1992741012-1019$.

3 Bratusch-Marrain PR, Smith D \& DeFronzo RA. The effect of growth hormone on glucose metabolism and insulin secretion in man. Journal of Clinical Endocrinology and Metabolism $1982 \mathbf{5 5}$ 973-982.

4 Hopwood NJ, Forsman PJ, Kenney FM \& Drash AL. Hypoglycemia in hypopituitary children. American Journal of Diseases in Childhood 1975129 918-929.

5 Jørgensen JOL, Møller J, Alberti KGMM, Schmitz O, Christiansen JS, Ørskov $\mathrm{H}$ et al. Marked effects of sustained low growth hormone (GH) levels on day-to-day fuel metabolism: studies in GH-deficient patients and healthy untreated subjects. Journal of Clinical Endocrinology and Metabolism 199377 1589-1596.

6 Fowelin J, Attvall S, Lager I \& Bengtsson B-Å. Effects of treatment with recombinant human growth hormone on insulin sensitivity and glucose metabolism in adults with growth hormone deficiency. Metabolism 199342 1443-1447.

7 Frohman LA, MacCillivray MH \& Aceto T. Acute effects of human growth hormone and insulin secretion and glucose utilisation in normal and growth hormone deficient subjects. Journal of Clinical Endocrinology and Metabolism 196727 561-567.

8 Sirek A, Vranic M, Sirek OV, Vigas M \& Policova Z. Effect of growth hormone on acute glucagon and insulin release. American Journal of Physiology 1979257 E107-E112.

9 Nielsen JH, Svensson C, Galsgaard ED, Møldrup A \& Billestrup N. Beta cell proliferation and growth factors. Journal of Molecular Medicine $19997762-66$.

10 Krarup T \& Groop PH. Physiology and pathophysiology of GIP: a review. Scandinavian Journal of Clinical and Laboratory Investigation $199151571-579$.

11 Nauck MA. Is glucagon-like peptide 1 an incretin hormone? Diabetologia 199942 373-379.

12 Ludvik B, Kautzky-Willer A, Prager R, Thomaseth K \& Pacini G. Amylin. History and overview. Diabetic Medicine (Suppl 2)1997 14 9-13.

13 Schmitz O, Nyholm B, Ørskov L, Gravholt C \& Møller N. Effects of amylin and the amylin agonist pramlintide on glucose metabolism. Diabetic Medicine (Suppl 2)1997 14 19-23.

14 Percy A, Trainor DA, Rittenhouse J, Phelps J \& Koda JE. Development of sensitive immunoassay to detect amylin and amylin-like peptides in unextracted plasma. Clinical Chemistry 199642 576-585.

15 Krarup T, Madsbad S, Moody AJ, Regeur L, Faber OK, Holst JJ et al. Diminished gastric inhibitory polypeptide (GIP) response to meal in newly diagnosed type 1-(insulin dependent) diabetics. Journal of Clinical Endocrinology and Metabolism 198356 1306-1312.

16 Ørskov C, Rabenhøj L, Kofod H, Wettergren A \& Holst JJ. Production and secretion of amidated and glycine-extended glucagon-like peptide-1 (GLP-1) in man. Diabetes $1994 \mathbf{4 3}$ 535-539.

17 Deacon CF, Pridal L, Klarskov L, Olesen M \& Holst JJ. Glucagonlike peptide-1 undergoes differential tissue-specific metabolism in the anesthetized pig. American Journal of Physiology 1996271 E458-E464.

18 Rosenfalck AM, Fisker S, Hilsted J, Dinesen B, Vølund AA, Jørgensen JOL et al. The effect of the deterioration of insulin sensitivity on $\beta$-cell function in growth-hormone-deficient adults following 4-month growth hormone replacement therapy. Growth Hormone and IGF Research 1999 9 96-105.

19 Boden G \& Jadali F. Effects of lipid on basal carbohydrate metabolism in normal men. Diabetes $199140686-692$.

20 Ørskov C. Glucagon-like peptide-1, a new hormone of the enteroinsular axis. Diabetologia 199235 701-711.

21 Thorens B, Porret A, Bühler L, Deng S-P, Morel P \& Widmann C. Cloning and functional expression of the human islet GLP-1 receptor. Diabetes $1993 \mathbf{4 2} 1678-1682$.

22 Nauck MA, Bartels E, Ørskov C, Ebert R \& Creutzfeld W. Additive insulinotropic effects of exogenous synthetic human gastric inhibitory polypeptide and glucagon-like peptide-1-(7-36) amide infused at near-physiological insulinotropic and glucose concentrations. Journal of Clinical Endocrinology and Metabolism 199376 912-917.

23 Qualman C, Nauck MA, Holst JJ, Ørskov C \& Creutzfeldt W. Insulinotropic actions of intravenous glucagon-like peptide-1 (736 amide) in the fasting state in healthy subjects. Acta Diabetologica 199532 13-16.

24 Ørskov C, Jeppesen J, Madsbad S \& Holst JJ. Proglucagon products in plasma of noninsulin-dependent diabetics and nondiabetic controls in the fasting state and after oral glucose and intravenous arginine. Journal of Clinical Investigation $199187415-423$.

25 Willms B, Werner J, Holst JJ, Ørskov C, Creutzfeldt W \& Nauck MA. Gastric emptying, glucose responses, and insulin secretion after a liquid test meal: effects of exogenous glucagon-like peptide-1 (GLP-1)-(7-36) amide in type 2 (noninsulin-dependent) diabetic patients. Journal of Clinical Endocrinology and Metabolism $1996 \mathbf{8 1}$ 327-332.

26 Ho KY, Veldhuis JD, Johnson ML, Furlanetto R, Evans WS, Alberti KGMM et al. Fasting enhances growth hormone secretion 
and amplifies the complex rhythms of growth hormone secretion in man. Journal of Clinical Investigation $1988 \mathbf{8 1} 968-975$.

27 Jørgensen JOL. Human growth hormone replacement therapy: pharmacological and clinical aspects. Endocrine Reviews 199112 189-207.

28 Nauck MA, Heimesaat MM, Ørskov C, Holst JJ, Ebert R \& Creutzfeldt W. Preserved incretin activity of glucagon-like peptide 1 (7-36 amide) but not of synthetic human gastric inhibitory polypeptide in patients with type 2 diabetes mellitus. Journal of Clinical Investigation 199391 301-307.

29 Pieber TR, Stein DT, Ogawa A, Alam T, Ohneda M, McCorkle K et al. Amylin-insulin relationships in insulin resistance with and without diabetic hyperglycemia. American Journal of Physiology 1993265 E446-E453.

30 Nyholm B, Møller N, Gravholdt CH, Ørskov L, Mengel A, Bryan G et al. Acute effects of the human amylin analog AC137 on basal and insulin-stimulated euglycemic and hypoglycemic fuel metabolism in patients with insulin-dependent diabetes. Journal of Clinical Endocrinology and Metabolism 199681 1083-1089.

31 Couce M, Kane LA, O'Brien TD, Charlesworth J, Soeller W, McNeish J et al. Treatment with growth hormone and dexamethasone in mice transgenic for human islet amyloid polypeptide causes islet amyloidosis and beta-cell dysfunction. Diabetes 199645 1094-1100.

Received 21 April 2000

Accepted 19 July 2000 